\title{
FIRST PERSON AND THIRD PERSON REASONS AND RELIGIOUS EPISTEMOLOGY
}

\section{LINDA ZAGZEBSKI}

University of Oklahoma

\begin{abstract}
In this paper I argue that there are two kinds of epistemic reasons. One kind is irreducibly first personal - what I call deliberative reasons. The other kind is third personal - what I call theoretical reasons. I argue that attending to this distinction illuminates a host of problems in epistemology in general and in religious epistemology in particular. These problems include (a) the way religious experience operates as a reason for religious belief, (b) how we ought to understand religious testimony, (c) how religious authority can be justified, (d) the problem of religious disagreement, and (e) the reasonableness of religious conversion.
\end{abstract}

\section{THE DISTINCTION BETWEEN FIRST PERSON AND THIRD PERSON REASONS}

\section{1 .}

I assume that believing $\mathrm{p}$ is a state in which I have settled for myself whether p. An epistemic reason is something on the basis of which I can settle for myself whether $\mathrm{p}$ in so far as my goal is truth, not benefit or some other practical or moral aim. I want to argue that there are two kinds of epistemic reasons, one irreducibly first personal, the other third personal, and that attending to the distinction illuminates a host of philosophical problems, including several that have special importance for philosophy of religion.

What I mean by theoretical reasons for believing $\mathrm{p}$ are facts that are logically or probabilistically connected to the truth of $\mathrm{p}$. They are facts 
(or propositions) about states of the world or experiences which, taken together, give a cumulative case for or against the fact that $\mathrm{p}$ (or the truth of p). ${ }^{1}$ They are not intrinsically connected to believing. We call them reasons because a reasonable person who comes to believe them and grasps their logical relations to $\mathrm{p}$ will see them as reasons for $\mathrm{p}$. They can be shared with others - laid out on the table, so they are third personal. They are relevant from anyone's point of view. In fact, they do not require a point of view to be reasons. The connections between theoretical reasons and what they are reasons for are among the facts of the universe. Theoretical reasons aggregate and can be used in Bayesian calculations. What we call evidence is most naturally put in the category of theoretical reasons, although the notion of evidence is multiply ambiguous. ${ }^{2}$ But when I mention evidence in this paper, I will mean facts that are in the category of theoretical reasons.

In contrast, what I mean by deliberative reasons have an essential connection to me and only to me in my deliberations about whether $\mathrm{p}$. Deliberative reasons connect me to getting the truth of $\mathrm{p}$, whereas theoretical reasons connect facts about the world with the truth of $\mathrm{p}$. Deliberative reasons do not simply provide me a weightier reason for $\mathrm{p}$ than they provide others. They are not reasons for other persons at all. They are irreducibly first personal.

To see the distinction I have in mind, consider experience as a reason for belief. If you have an experience, the fact that you have it is a theoretical reason for believing a variety of propositions. You can tell me about your experience, and if I believe what you tell me, I can then refer to the fact that you had the experience as a reason to believe whatever it supports. You and I can both refer to the fact that you had the experience as a reason to believe something, and so can anybody else who is aware of the fact that you had the experience. The fact that the experience occurred is therefore a theoretical reason. It is on the table for all to consider, and all can consider its logical and probabilistic connections to other facts about the world.

However, you are in a different position than I am with respect to your experience because you not only grasp the fact that you had the experience;

\footnotetext{
${ }^{1}$ In this paper I do not distinguish facts from true propositions. If there is a difference, the argument of this paper can be easily amended.

${ }^{2}$ For an excellent survey of the different senses of evidence, see Thomas Kelly's entry, "Evidence," in the Stanford Encyclopedia of Philosophy (http://plato.stanford.edu/entries).
} 
in addition, you and you alone had the experience. That experience affects many of your reasoning processes, emotional responses, and the way you come to have or give up certain beliefs directly, and that is quite proper. In contrast, the fact that you had the experience is something you and I and many other people can come to believe. My way of describing the contrast is that your experience gives you a deliberative reason to form certain beliefs, whereas the fact that the experience occurred gives anybody a theoretical reason to form certain beliefs. ${ }^{3}$ Anybody can form the belief that you had the experience, thereby accessing that fact, but nobody but you can have your experience.

Another type of deliberative reason is what are loosely called intuitions in one of its senses. I will not attempt an account of intuition, but what I have in mind is, very roughly, something internal to the mind that responds with an answer to a question, often as a response to a concrete case. For example, if a fat man is stuck in the mouth of a cave, is it morally permissible to blow him out of the cave to save yourself and the other speelunkers from drowning in the rising tide? My intuition might be no, but perhaps yours is yes. I have no position on the strength of an intuition of this kind as a reason to believe what the intuition supports. Maybe it is strong, maybe it is not. But in so far as it is a reason at all, it is a deliberative reason. My intuitions are mine alone, and they give me but not you a particular kind of reason for certain beliefs. But again, the fact that I have an intuition can be put out on the table. I can tell you that my intuition is such and such, and that then becomes a theoretical reason supporting some position. So the fact that most people think that Gettier cases are not cases of knowledge is a reason for anyone to reject a theory that has the consequence that the believer knows in a Gettier situation, but your own intuition about such cases is a reason for you alone to draw certain conclusions. Intuitions, then, are like experiences. The intuition and the experience provide the agent with first person reasons to believe something, but the fact that the experience occurred or that the intuition is what it is can be treated as evidence, as a theoretical reason for the truth of some proposition.

\footnotetext{
${ }^{3}$ My use of the terms "theoretical" and "deliberative" is not essential to the contrast I am making, but the terms call attention to a difference in function that I find helpful.
} 
I propose that there is another important deliberative reason that is more basic for us than any theoretical reasons we can identify. We can see the need for such a reason by reflecting on the need for a link between third person reasons and something in myself. Theoretical reasons do not operate as reasons for me to believe anything until I take them on board. But my taking a certain set of theoretical reasons for $\mathrm{p}$ as reasons to believe $\mathrm{p}$ is not sufficient in itself to make it likely that $\mathrm{p}$ is true. That is because my taking a set of theoretical reasons to be reasons to believe $p$ is irrelevant to the actual connection between those reasons and $p$ unless I have taken them properly - properly identified the facts, figured out the correct logical and probabilistic relations between those facts and p, have appreciated the significance of individual facts, and have not left anything out. But my reasons to believe that depend upon the more basic belief that my faculties are trustworthy. And that raises the question of what reasons I have to believe that my faculties are trustworthy. It has been pointed out by others that any such reasons are circular. I have no way of telling that my faculties in general get me to the truth without using those faculties.

A reasonable response to the phenomenon of epistemic circularity is epistemic self-trust. ${ }^{4} \mathrm{I}$ am not arguing here that no other response is reasonable (although it is my position that no other response is as reasonable). But I am claiming that it is reasonable to believe my faculties are generally trustworthy, and it is reasonable to dispel doubt about the trustworthiness of my faculties or hold such doubt at bay, a doubt that naturally arises upon reflection about the phenomenon of epistemic circularity. I think that means that in addition to including the belief that I am generally trustworthy, self-trust includes an affective component, a component of feeling trusting. That is because doubt is partly affective, and it takes an affective state to dispel it. It is in virtue of self-trust - a state that is partly affective, that I take theoretical reasons I identify to point to the truth of some proposition $\mathrm{p}$, and I am reasonable in doing so.

I said above that a reason to believe $\mathrm{p}$ is a state in virtue of which it is reasonable to think some proposition $\mathrm{p}$ is true. It so, self-trust

\footnotetext{
${ }^{4}$ See Richard Foley, Intellectual Trust in Oneself and Others (Cambridge University Press, 2001) and William Alston, Beyond Justification: Dimensions of Epistemic Evaluation, (Cornell University Press, 2005).
} 
is a reason because it is in virtue of self-trust that I believe that what I take to be theoretical reasons for believing $\mathrm{p}$ are truth-indicators, and that is a reasonable thing to do. Self-trust is a reason, but a reason of a distinctively first personal kind. It is a second order reason because it is a reason to believe that I have properly identified theoretical reasons for a belief. The way self-trust gives me a deliberative reason to think I am properly connected to theoretical reasons shows that there are deliberative reasons that are more basic for me than any theoretical reasons I can identify. Of course, they are not more basic than theoretical reasons, which are facts of the universe. But they are more basic than my use of any theoretical reasons in deliberations about what the truth is.

Deliberative reasons can therefore be first order reasons like experience or intuition, or second order reasons like self-trust. I want to argue next that trust in myself (a deliberative reason) can give me a reason to trust others (another deliberative reason). So a deliberative reason can be a reason to have other deliberative reasons.

How does self-trust give me a reason to trust others? My position is that if, in believing in a way I trust, I come to believe that others have the same faculties I trust in myself, then given the a priori principle that I ought to treat like cases alike, I have a reason to trust their faculties. If I reasonably trust their faculties, I have a reason to believe the deliverances of their faculties. Trust in someone else gives me a deliberative reason to believe some proposition $\mathrm{p}$ because my reason is based on their similarity to me and my trust in myself. ${ }^{5}$

If I am right that trust is partly an affective state, and if I am also right that trust can give me a reason to believe $\mathrm{p}$, then a state that is partly affective can give me a reason to believe $\mathrm{p}$. This is an epistemic reason, not a practical or moral reason. I think that there are probably other affective states that are deliberative reasons for belief. One is the emotion of admiration. I may epistemically admire someone and trust that admiration upon reflection. Admiration for a person can give me a reason to think that she has the truth in some domain that includes $\mathrm{p}$, and it can give me a reason to try to imitate her in a way that includes

\footnotetext{
${ }^{5}$ I defend the argument of this paragraph in detail in Epistemic Authority: A Theory of Trust, Authority, and Autonomy in Belief, based on my 2010 Wilde Lectures and my 2011 Kaminski Lectures (manuscript in progress), chap. 3.
} 
coming to believe $\mathrm{p}$. In that case my admiration for her is a deliberative reason to believe $\mathrm{p}$. There are no doubt theoretical reasons to admire her, but those are not the reasons for believing p. ${ }^{6}$

Deliberative reasons to believe $\mathrm{p}$ because of trust or admiration for another person are not necessarily reasons to think that the other person has theoretical reasons for $\mathrm{p}$. Of course, it often happens that a person who has the truth whether $\mathrm{p}$ also has theoretical reasons to believe $\mathrm{p}$, but my reason to think someone has the truth whether $\mathrm{p}$ is not the same as reason to think that she has theoretical reasons to believe p. Even if she has theoretical reasons for $\mathrm{p}$, that is not what I have reason to believe. Deliberative reasons like trust and admiration are higher order reasons to think that I or someone else has the truth whether $\mathrm{p}$, and therefore has reason to believe $\mathrm{p}$, but the reason may be deliberative rather than theoretical.

We have looked at a number of kinds of deliberative reasons: an experience, an intuition, trust in myself, trust in others, admiration. The first two have a third person analogue that is a theoretical reason. The fact that someone had an experience, and the fact that someone has an intuition can be treated by anybody as a theoretical reason to believe $\mathrm{p}$. Trust and admiration are different. The fact that you trust something or admire someone is not a theoretical reason. It is not the kind of reason that can be put out on the table for all to consider in favor of the truth of some proposition. It may, however, be a deliberative reason.

\section{2.}

There are important differences between theoretical and deliberative reasons that require us to think of them in distinct categories. First, deliberative reasons and theoretical reasons do not aggregate. That follows from the first person character of deliberative reasons and the third person character of theoretical reasons. They cannot aggregate because nobody has figured out how to put the first person and third

\footnotetext{
${ }^{6}$ The fact that there are theoretical reasons to admire someone in the domain of her believing $\mathrm{p}$ is not sufficient to give me a theoretical reason to believe $\mathrm{p}$ because reasons are not transitive. If $\mathrm{A}$ is a reason for $\mathrm{B}$ and $\mathrm{B}$ is a reason for $\mathrm{C}$, it does not follow that $\mathrm{A}$ is a reason for $\mathrm{C}$. So if $\mathrm{A}$ is a set of theoretical reasons to admire Sarah, and admiring Sarah is a reason to imitate her in believing $\mathrm{p}$, it does not follow that theoretical reasons A gives me reason to believe $\mathrm{p}$.
} 
person points of view together. Deliberative reasons neither increase nor decrease the theoretical case for some proposition p. My deliberative reasons are not facts of the universe that affect the theoretical case for $\mathrm{p}$, and I can grasp that even if $I$ am the one giving the theoretical case. So suppose I am giving the case for the proposition that driving while talking on a mobile phone is dangerous. I would point to the studies by reliable researchers that show that people who talk on the phone while driving have reduced peripheral vision, slower response time, and a higher accident rate than people who do not, but I would not add that I trust the people who did the studies and they believe its conclusion (studies of that sort rarely even mention the personal conclusion drawn by the researchers). The fact that people I trust believe what they believe or have certain epistemic qualities does not make the relationship between the data in the studies and the conclusion stronger. To refer to it when giving the evidence linking mobile phone use and auto safety is beside the point. If driving while on the phone is dangerous, it does not matter what anybody anywhere thinks about it. Of course, I might cite my experience while driving on the phone as a reason for me to believe it is unsafe, and you could cite the fact that I had that experience when giving your theoretical reasons for the same conclusion. But when you cite the fact that I had the experience as a theoretical reason for believing that talking on the phone while driving is unsafe, you are not referring to the same thing to which I refer when I cite my experience.

Although deliberative reasons and theoretical reasons do not aggregate, they are both kinds of reasons to think some proposition is true. Together they can increase or decrease my confidence that $\mathrm{p}$. So if I believe $\mathrm{p}$ based on theoretical reasons and then find out that you believe $\mathrm{p}$ too, that increases my confidence that $\mathrm{p}$. But while it is true that finding out that you believe $\mathrm{p}$ increases my confidence in myself in the way I come to believe $p$, and therefore increases my confidence in $p$, it is not additional theoretical evidence for $\mathrm{p}$. If we were listing the facts of the universe that indicate the dangers of driving on the phone, we would not list the people who believe that it is dangerous.

Reasons do not aggregate in the other direction either. I might believe p because of deliberative reasons - say, it is because I epistemically trust you and you believe $\mathrm{p}$. Then I get a piece of evidence that $\mathrm{p}$ and that increases my confidence that $\mathrm{p}$. In that case it might appear that 
the theoretical reason increases the force of my deliberative reason; it increases my trust in you. But that also is a mistake. Getting a piece of evidence for $\mathrm{p}$ does not support my trust in you when you believe $\mathrm{p}$. It shows that your conclusion is more likely to be correct, and so I am more confident in $p$, but even if I got heaps of evidence for $p$, that should not increase my confidence that you are trustworthy in the way you came to your belief $\mathrm{p}$. I could get evidence that you are trustworthy, but that is not part of the theoretical case for $\mathrm{p}$. It is part of the theoretical case that you are trustworthy.

I am not claiming that the beliefs of others cannot be treated as evidence. I could get evidence that you are reliable in some domain and evidence that you have a belief in that domain. That would give me a theoretical reason to have the belief. It could be put out on the table as inductive evidence for the truth of the belief. That is not the same as the trust I have in you that can give me a deliberative reason to believe what you believe or what you tell me. I have described trust as a state that is partly epistemic and partly affective, and trust in others arises because it is a commitment of my attitude towards myself. A judgment of reliability is a third person judgment that involves nothing about personal relations or agency. In a judgment of reliability a person is treated no differently than a thermometer or a calculator.

Theoretical reasons aggregate with each other since they are thirdpersonal. Deliberative reasons can affect other deliberative reasons, but your deliberative reasons do not aggregate with mine. Nonetheless, your deliberative reasons can affect mine. If I trust you and you tell me that you trust someone else or some authoritative body, I might take that as a reason to trust that person or body. But if I do not trust you and you tell me you trust yourself or someone else, your trust is irrelevant to me. Your deliberative reasons are relevant to me only in so far as they connect with my deliberative reasons.

There is another interesting difference between theoretical reasons and deliberative reasons. I have no control at all over the relation between theoretical reasons for $\mathrm{p}$ and $\mathrm{p}$, but I exercise executive control over deliberative reasons. It is because of my deliberative reasons that what 
I believe is up to me. ${ }^{7}$ am not suggesting that deliberative reasons are voluntary, but my agency is involved in deliberative reasons, whereas it is irrelevant to theoretical reasons. By the nature of deliberative reasons, they connect me and the exercise of my reflective faculties with the aim I have in exercising those faculties in the domain of belief. For present purposes I am assuming the aim is truth, although we can also have deliberative reasons to think that our faculties connect us to other epistemic ends such as understanding.

To summarize what I have said so far:

- Theoretical reasons are $3^{\text {rd }}$ personal, deliberative reasons are $1^{\text {st }}$ personal.

- Theoretical reasons have no essential connection to belief; deliberative reasons are essentially connected to my deliberations about what to believe.

- Theoretical and deliberative reasons do not aggregate. Deliberative reasons for me to believe $\mathrm{p}$ do not increase the theoretical case for $\mathrm{p}$. Theoretical reasons for $\mathrm{p}$ do not increase my deliberative reasons for believing $\mathrm{p}$.

- There are deliberative reasons that are always more basic than any theoretical reasons I can identify.

- I have no control over theoretical reasons, whereas deliberative reasons are reasons for me as an agent and I use them as an agent.

Both theoretical and deliberative reasons are reasons, and they are truth-directed. They are epistemic, not practical. Theoretical reasons are facts that support the truth of the proposition p. Deliberative reasons are reasons that support my believing $\mathrm{p}$ in so far as my aim is truth. They are reasons that support $m y$ believing $\mathrm{p}$ rather than your believing $\mathrm{p}$. Both deliberative reasons and the theoretical reasons I identify increase my confidence in my belief $\mathrm{p}$.

The distinction I am proposing is not the same as the distinction between first order and second order epistemic reasons. There are both first order and second order theoretical reasons and first order and second order deliberative reasons. As I have said, the fact that an

${ }^{7}$ For a different kind of defense of the position that what I believe is "up to me," see Richard Moran in Authority and Estrangement: An Essay on Self-Knowledge (Princeton University Press, 2001). 
experience occurred is a first order theoretical reason for various beliefs; the experience is a first order deliberative reason. The fact that a certain person is reliable is a second order theoretical reason to believe what she believes; my epistemic trust in that person is a second order deliberative reason.

The distinction between agent-relative and agent-neutral reasons in ethics is closer to the distinction I am drawing here. ${ }^{8}$ There are different ways to characterize agent-relative reasons, but sometimes an agentrelative reason is treated as a reason other persons can have, but it has a different force for the agent than for others. For example, everyone has a reason to prevent murders, but the agent has a special reason not to commit a murder herself. In contrast, what I mean by a deliberative reason is a reason only a certain person can have. ${ }^{9}$

In addition, agent-relative reasons are generally treated as reasons that, while applying in a special way to a particular agent, are reasons for that agent because of some general principle. In this way of looking at reasons, agent-relative reasons are recognizable by persons other than the agent as reasons for that agent independent of the agent's deliberations. So, for example, my agent-relative reason not to commit a murder is not dependent upon my view of the matter. Everyone knows in advance that I have such a reason, and it is not up to me whether that reason applies to me. In contrast, I have proposed that deliberative reasons are connected with the agent's agency, and it is possible that whether something is a deliberative reason for her in some situation is up to her.

${ }^{8}$ Thomas Nagel is generally credited with introducing a form of this distinction in The Possibility of Altruism (Princeton: Princeton University Press, 1970), where he distinguished subjective and objective reasons for action. Derek Parfit introduced the terms "agent-relative" and "agent-neutral" reasons in Reasons and Persons (Oxford: Clarendon Press, 1984), and Nagel subsequently adopted this usage. For an overview of different approaches to this distinction and their respective merits, see Michael Ridge, "Reasons for Action: Agent-Neutral vs. Agent-Relative," Stanford Encyclopedia of Philosophy (http://plato.stanford.edu/entries).

${ }^{9}$ Derek Parfit refers to this difference as the difference between Nagel's distinction and his own very similar distinction. Parfit says: "Nagel's subjective reasons are reasons only for the agent. I call these agent-relative. When I call some reason agent-relative, I am not claiming that this reason cannot be a reason for other agents. All that I am claiming is that it may not be." (Parfit, 1984, p. 143). In this respect my distinction is more like Nagel's than Parfit's. 
That is a substantive claim about deliberative reasons that might not affect the way the distinction is made, so perhaps the terminology of agentrelative and agent-neutral epistemic reasons is an appropriate usage for the distinction I have described in this paper. I have no objections to using that terminology, provided that the differences between my way of characterizing the two kinds of reasons and its usage by other authors is recognized.

\section{APPLYING THE DISTINCTION TO PROBLEMS IN RELIGIOUS EPISTEMOLOGY}

\section{1.}

The distinction between theoretical and deliberative reasons makes it easier to understand a number of epistemic phenomena. First, it explains the puzzle of how experience can be a reason for belief, the enduring problem of the foundation of empirical knowledge. The problem is that the relation between my experience and a proposition I come to believe based on that experience is different in kind from the relation between one of my beliefs and another. There is no way to solve this problem by turning experiences into facts or propositional beliefs in an attempt to make all reasons theoretical. The fact that I have a certain sensory experience of seeing yellow gives me a theoretical reason to believe there is something yellow there, but my grasp of the fact that I have the experience of seeing yellow must itself be justified by the experience of seeing yellow. The foundation of empirical knowledge is not a propositional belief, much less some neutral fact about the universe, but something of an entirely different kind, and the relation between an instance of that kind and a propositional belief differs qualitatively from the relation between one propositional belief and another.

The distinction between two kinds of epistemic reasons can be used to explain this difference. An experience is a deliberative reason for the person who has the experience to form certain beliefs. Those beliefs then give her theoretical reasons to form certain other beliefs when she grasps the relation between those reasons and what they are reasons for. Since we already know that the link between experience and belief has to be different in kind from the link between one belief and another, we seek 
an explanation for the difference, and the difference between first person and third person reasons gives us such an explanation.

This distinction is important for the rationality of religious belief based on religious experience. A religious experience gives the subject an irreducibly first person reason for belief, one that differs qualitatively from the relation between the fact that the experience occurred and a belief it supports, a relation to which anyone has access, in principle. The distinction between the two kinds of reasons is particularly important for religious experience because religious experience may be uncommon within a population, and that makes it difficult for many people to access the fact that a religious experience has occurred. It is not unreasonable for someone to be skeptical about the evidential support given to a religious belief by the fact that someone else had a religious experience if experiences of that kind are qualitatively different from any experiences that person has had. We usually think that a religious experience is a stronger reason for religious belief for the person who has the experience than for other persons, but I think it is important to recognize a qualitative difference, not merely a difference in degree. In my opinion, discussion of religious experience as grounds for religious belief is advanced by focusing on the way deliberative reasons operate in a rational person. The process is very different when the only relevant reasons are theoretical.

\section{2.}

The distinction between the two kinds of reasons also makes it easier to understand the practice of testimony, which can be interpreted either as giving the recipient a theoretical reason for a belief or as giving her a deliberative reason. Most of the literature on testimony treats it as giving the recipient a theoretical reason. According to the reductionist model, the recipient makes an inductive inference from the evidence that a testifier is reliable in the relevant domain and that she has testified that $\mathrm{p}$, to the conclusion that $\mathrm{p}$. Anything can be treated as evidence, and there is nothing preventing a person from making such an inference. When she does so, she has a third person reason to believe what another persons says. Many so-called non-reductionists also see testimony as giving the subject evidence for belief, only they think the evidence is direct rather 
than inferential. ${ }^{10}$ In these evidence models, the testifier is treated the same way we treat a computer or a clock. The testifier gives anybody in similar circumstances a reason to believe the testimony.

But given what I have said, I cannot consistently treat other persons as simply sources of evidence (theoretical reasons) for me. It is because of trust in myself that I must trust them. When I trust someone else and they believe in a way I trust, I have a deliberative reason to believe the same thing. The person I trust may tell me what she believes in a way that expresses an intention that I believe it too. When she does so, she is asking me for trust, and if I grant it, I come to believe what she tells me on her word. There is a relationship between the testifier and myself in which each of us plays a role. The testifier assures me, the recipient, that $\mathrm{p}$ is true and that she has taken the responsibility to make the belief justified (or in my preferred terminology, epistemically conscientious). I rely upon her for the conscientious formation of the belief and defer to her if challenged. ${ }^{11}$ Since telling involves an interpersonal relationship on this model, there is a sense in which belief on testimony is within the control of the recipient. The evidence view of testimony cannot explain that. The evidential view makes it a mystery how asking for trust and granting it can provide a reason for anybody to believe something. It does not seem to be in the right category to be a reason for belief. ${ }^{12}$ But we can see why the evidence view of testimony exists. It is the view a person is forced to have if the only epistemic reasons she recognizes are theoretical.

${ }_{10}$ This is a point made by Benjamin McMyler, Testimony, Trust, and Authority, forthcoming, Oxford University Press, 2011, chaps 2 and 3. McMyler argues that testimony gives the recipient a second-person reason to believe what is testified. I have no objection to calling trust in others a second person epistemic reason for belief. Trust in you as a reason to believe something includes an irreducible reference to me. The important point for my argument here is that trust in others is clearly distinguishable from theoretical reasons, and it has the properties of first person, deliberative reasons.

${ }^{11}$ This model is close to the Assurance model of testimony of Richard Moran, "Getting Told and Being Believed," in The Epistemology of Testimony, edited by J. Lackey and E. Sosa (Oxford University Press, 2005), pp. 272-306.

${ }^{12}$ As Richard Moran says, it seems as if my recognizing the speaker's intention ought to be pointless. It does not add to my evidence as interpreter to learn that in addition to his believing p, the speaker also has the intention that I should believe p. See "Getting Told and Being Believed," p. 15. Moran mentions Paul Grice's much earlier use of that point. 
The interpretation of the practice of testimony is important for religious epistemology because divine revelation is testimony from God. On the evidence model of testimony, divine testimony gives the recipient either direct or inferential evidence for the content of the testimony. So belief on revelation can be interpreted as based on an inference that the source of some putative revelation is divine and hence reliable, the position of John Locke. ${ }^{13}$ Alternatively, divine testimony can be interpreted as direct evidence for the content of the testimony. Anti-reductionists about testimony typically follow Thomas Reid, who thought of belief on testimony as directly justified in the way he thought perceptual beliefs are directly justified by perceptual experience. On this model, the recipient of divine testimony has direct evidence for the truth of the testimony. Notice that the adherent of this approach agrees with Locke that a revelatory event is evidence for the recipient. The difference is that this view makes the evidence non-inferential, whereas Locke makes it inferential.

But if central cases of testimony give the recipient deliberative rather than theoretical reasons for belief, it seems to me that revelation should be treated differently. The ground of belief in revelation is trust in God, and that gives me a deliberative reason to believe what God tells me. When God tells me that $\mathrm{p}$, God takes responsibility for the truth of $\mathrm{p}$ for me and for all other intended recipients of his revelation. God intends that I believe him, and he acknowledges that we who are the recipients place epistemic trust in him by believing him. Our responsibility is to trust appropriately. It is God's responsibility to make the belief true.

There are a number of different ways trust can be an appropriate deliberative reason to believe testimony from God. Some people's trust is grounded in other deliberative reasons such as religious experience or the admiration they have for the Scriptural message.

My view is that trust in another person is justified by my conscientious judgment that trusting that person will survive my own conscientious

\footnotetext{
${ }^{13}$ See Locke, "Of Faith and Reason, and Their Distinct Provinces," in Essay Concerning Human Understanding, Bk. IV, Ch. 18, Sec. 7. See also Locke's posthumously published essay, "A Discourse of Miracles."
} 
self-reflection. ${ }^{14}$ Believing a person who is currently speaking to me or who has written a book or sent me an email is not very mysterious, but believing God requires a theory of revelation to explain how communication between God and me can succeed. My point here is not to give a theory of revelation, but to point out that a theory of revelation must respect the way in which testimony operates between two persons. If testimony involves a personal request for trust and a granting of trust, that element must be a component of an account of divine revelation.

\section{3 .}

The distinction between theoretical and deliberative reasons also helps us avoid confusion in framing the currently popular topic of reasonable disagreement. Suppose I believe $\mathrm{p}$ and you believe not $\mathrm{p}$. We get together and compare our evidence, so now we have all the same evidence. Our evidence can include the facts that we have each had certain experiences. We now have the same theoretical reasons. A problem arises when, in addition to the evidence on the table, I know that you believe not $\mathrm{p}$ and I trust you in the way you acquired your belief not $\mathrm{p}$. I now seem to have a weaker case for $\mathrm{p}$ than I had before.

This situation is not especially problematic if we think of the conflict as arising within one's theoretical reasons. Theoretical reasons may or may not include facts about people's beliefs. Let us suppose first that they do. The issue, then, is that one reliable person who happens to be me believes $\mathrm{p}$, but another reliable person who happens to be you believes not $\mathrm{p}$. This conflict is no different than the conflict that arises when neither of the persons with conflicting beliefs is myself. It is the common problem of a clash in evidence, and it is presumably resolved by awaiting more evidence. In any case, there is no special problem when the disagreement between myself and another is interpreted as this sort of conflict within theoretical reasons.

There is another way the person who sees the problem as a conflict within theoretical reasons can look at the situation. They might exclude from the evidence the fact that the believers have the beliefs they have. The idea is that persons are simply conduits for communicating evidence

\footnotetext{
${ }^{14} \mathrm{I}$ defend this idea as the ground for epistemic trust and belief on the authority of individuals and communities in Epistemic Authority, cited in note 3.
} 
to each other. Once the evidence is on the table, it does not matter what anybody believes. What someone believes is a fact about what they do with the evidence; it is not evidence. It might appear that we are forced to draw this conclusion because we do not treat our own belief as evidence. If I am considering the case for and against $\mathrm{p}$, once I start to believe $\mathrm{p}$, I do not think that then I have additional evidence for $\mathrm{p}$. My believing $\mathrm{p}$ does not increase my theoretical case for $\mathrm{p}$. But if $m y$ believing $\mathrm{p}$ has no effect on the case for $\mathrm{p}$, your believing $\mathrm{p}$ should have no effect either. What people believe is not part of the theoretical reasons for belief. On this approach disagreement is not a problem.

If the only reasons for belief are theoretical, then, disagreement is a problem of evidence pointing in conflicting directions, which is not mysterious or surprising, or it is no problem at all. But reasonable people do experience their disagreement with other reasonable people as a problem, and it is necessary to explain that. Suppose I believe $\mathrm{p}$ and I have certain theoretical reasons upon which I base my belief. As I have argued, my confidence in $\mathrm{p}$ is not determined solely by those reasons because those reasons by themselves are not sufficient to justify me in believing $\mathrm{p}$ in a non-circular way. I must also trust that my faculties have properly handled the evidence, which means not only that I have figured out the correct logical and probabilistic relations between the evidence and $\mathrm{p}$, but that I appreciate the significance of individual pieces of evidence, and that I have not left anything out. I need to trust that I have used my faculties well and have the relevant intellectual virtues. But given that my confidence in my belief $\mathrm{p}$ depends upon the above, and given that my trust in myself commits me to trust others who are relevantly like myself, the fact that someone else who is relevantly like me believes not $\mathrm{p}$ gives me a reason to trust his belief not $\mathrm{p}$ and to distrust my belief $\mathrm{p}$. The problem of reasonable disagreement is therefore a problem that arises among my deliberative reasons.

When we consider deliberative reasons for belief, that gives us a different response to the argument that your belief should not count as evidence for me unless mine does also. If a belief is formed in a way I trust, that does give me a deliberative reason to believe it. The perhaps surprising conclusion that if $I$ form a belief $\mathrm{p}$ in a way I trust, that gives me a deliberative reason to (continue to) believe p, just as your believing not $\mathrm{p}$ in a way I trust gives me a deliberative reason to believe not $\mathrm{p}$. 
The objector who claims that your belief does not give me a reason to believe anything unless mine does also is correct. There is a symmetry between your belief and mine as reasons for belief. Neither belief gives me a theoretical reason to believe. Both beliefs give me a deliberative reason to believe. The problem of disagreement arises when I trust both myself and someone else who has a conflicting belief.

Religious disagreement was recognized as a problem for religious belief well before the topic of reasonable disagreement drew attention from epistemologists. What people did not do was to reason as follows: I and my co-religionists are reliable people and we believe p. The believers in these other religions are also reliable people and they believe not $\mathrm{p}$. If that was what they were thinking, the conflict in their evidence would not have been very interesting, as I said. But people also did not take the other approach to disagreement within theoretical reasons mentioned above. That is, they did not say that the conflicting beliefs of other people are irrelevant because beliefs are not evidence. They were presumably worried about something else. Many people found that their experiences of close association with persons in other religious communities led them to place a substantial amount of trust in those persons, and consequently in their beliefs. They interpreted their trust in those others as giving them a reason to believe what the others believed, a reason that conflicted with the reasons they already had to believe in their own religion due to trust in themselves. It is very difficult to explain why this kind of experience leads to a clash of reasons for belief unless we are talking about deliberative reasons.

\section{4 .}

The difference between theoretical and deliberative reasons also explains the primary feature of acting or believing on authority. According to Joseph Raz, the distinguishing feature of authoritative directives is that they give the subject a pre-emptive reason to obey the authority, where a pre-emptive reason is a reason that replaces the subject's other reasons for and against performing the act. For instance, if I stop at a red light on the authority of the law, then the fact that the law requires me to stop is my reason for stopping, a reason that replaces any other reasons 
I have for and against stopping at the light. ${ }^{15} \mathrm{I}$ will not argue here that acting on authority in this way can be justified. My point is only that acting on authority is something people do, and what they are doing is to treat their reasons for acting as the authority dictates in a certain way, one in which the authority's directive becomes the reason for the act, replacing other reasons. But it is very hard to see how one reason can replace another when both reasons are theoretical. In order to let one reason replace others, I, the subject, must take the authority's directive as having a certain force for me. I am free to take it as authoritative or not. I therefore exercise the executive function of an agent when I act on authority. My reason to do so must therefore be deliberative.

I argue that the same point applies to believing on authority as to acting on authority. My position is that the belief or testimony of another person whom I conscientiously take to be more trustworthy than myself in some domain can give me a pre-emptive reason to believe what the authority believes or testifies. ${ }^{16}$ The distinction between theoretical and deliberative reasons makes it easier to see how this can happen. The fact that the authority has a belief p pre-empts my theoretical reasons for and against $\mathrm{p}$. But pre-emption seems strange if all epistemic reasons are theoretical.

The rationality of taking religious beliefs on authority gets very little attention in religious epistemology and I would like to see that change. I believe that it can be reasonable to take a religious belief pre-emptively out of trust in a religious authority. My reason to take a belief on authority is deliberative. It depends upon a certain connection between the authority and myself, and I exercise the control of an agent when I do so.

The erosion of trust in authority in modern life includes the loss of reasons to believe or act as the authority directs. Religious communities have much to contribute to our understanding of building and rebuilding the relationships that give persons deliberative reasons to trust authority. In fact, religious communities may be the most important kind of community in which trust in persons with whom one lacks a direct relationship still exists. I propose that an investigation of the reasons why members of religious communities accept authority in their community

\footnotetext{
${ }^{15}$ Joseph Raz, The Morality of Freedom (Oxford: Clarendon Press, 1988).

${ }^{16} \mathrm{I}$ argue for this view in Epistemic Authority, chap. 5.
} 
will lead nowhere if we expect the reasons to be theoretical, but will be enlightening if we attend to deliberative reasons.

\section{5 .}

Finally, I think that conversion cannot be explained except by deliberative reasons. Rarely does anyone convert to a religion because of theoretical reasons he did not previously have. But conversion is sometimes the reasonable thing to do. Trust or admiration for another person or for a tradition or for the sacred texts of a religion is typically the reason for conversion, not just the cause. The fact that conversion can be reasonable is very difficult to explain without reference to deliberative reasons. Of course, someone who maintains that the only kind of epistemic reasons are theoretical will deny that it is ever rational to change one's epistemic stance towards a proposition (belief, disbelief, withholding belief) when one's apprehension and evaluation of the theoretical reasons do not change, but my purpose in this paper is not to convince anyone of the rationality of conversion. I mention conversion as an example of a phenomenon of change of belief that many people do find rational, which deserves more attention in the literature, and which I conjecture cannot be explained except by reference to deliberative reasons. ${ }^{17}$

\section{CONCLUSION}

In this paper I have proposed that distinguishing first person from third person epistemic reasons permits us to get a better understanding of some important problems in epistemology in general and religious epistemology in particular. The problems I have mentioned have something in common. They reveal the way human agency operates in the attempt to get the truth, not just in human action in the overt sense of action. The nature of the self and its executive power to manage

${ }^{17}$ For a classic historical account of the rise of conversion as a phenomenon in the West, see A.D. Nock, Conversion (Baltimore, MD: John Hopkins University Press, 1998). Nock argues that in the ancient world people could be converted to philosophies such as Pythagoreanism, Platonism, Epircureanism, and Stoicism, but not to the ancient Greek or Roman religions. Conversion became important with the rise of Christianity because Christianity included answers to the ultimate questions posed by philosophers, yet it was also in competition with pagan religion since it required people to make a choice. 
itself is such a difficult problem, it is unsurprising that epistemologists often prefer to bracket it off from the problems of direct interest to epistemology. But if I am right, we cannot do that without distorting the relationship between epistemic reasons and what they are reasons for. What $I$ reasonably take to be reasons to believe some proposition $\mathrm{p}$ is not identical to the neutral facts that any reasonable person would take to be reasons supporting $\mathrm{p}$. But as a reasonable person I must figure out how to combine theoretical and deliberative reasons in my epistemic psychology in a way that gives me a determinate answer to the question whether $\mathrm{p}$. It is particularly important that we do not ignore the distinction between the two kinds of reasons in the domain of religious belief since religious belief is a particular person's answer to her own religious questions, yet its content is also the property of all reasonable persons in their common attempt to find the truth. 